antibodies. His vision recovered postoperatively. He was given cranial irradiation and hormone replacement treatment with desmopressin thyroxine, and cortisone acetate. Growth was static 18 months after surgery, and plasma growth hormone and prolactin concentrations were undetectable.

\begin{tabular}{|c|c|c|c|}
\hline$\underset{(h)}{\operatorname{Time}}$ & $\begin{array}{l}\text { Glucose } \\
(\mathrm{mmol} / \mathrm{l})\end{array}$ & $\underset{(\mathrm{mU} / 1)}{\text { Insulin }}$ & $\begin{array}{c}\text { Growth hormone } \\
(\mathrm{mU} / \mathrm{l})\end{array}$ \\
\hline $\begin{array}{l}0 \\
0 \cdot 5 \\
1 \cdot 0 \\
2 \cdot 0 \\
3 \cdot 0 \\
4 \cdot 0\end{array}$ & $\begin{array}{l}3.8 \\
4 \cdot 7 \\
4.0 \\
3.8 \\
3.4 \\
3.1\end{array}$ & $\begin{array}{r}9.7 \\
12.5 \\
12.1 \\
37.8 \\
33.4 \\
12.9\end{array}$ & $\begin{array}{l}1.4 \\
1.2 \\
1.2 \\
1.3 \\
1.9 \\
2.5\end{array}$ \\
\hline
\end{tabular}

\section{Discussion}

Pituitary apoplexy associated with gigantism in childhood is rare. Our patient is the youngest patient with pituitary apoplexy to have been reported on. ${ }^{3}$ Impairment of the infundibular circulation by impaction of the enlarging tumour at the diaphragmatic notch may cause infarction or haemorrhage, or both, into the pituitary gland. ${ }^{1}$ Once this process occurs the tumour mass expands beyond the site of the original adenoma and may lead to typical symptoms of raised intracranial pressure.

Previous reports of pituitary apoplexy in acromegaly have mentioned considerable improvement in clinical signs after the apoplectic episode. In most cases hypopituitarism occurs with a pronounced decrease in growth hormone concentrations. ${ }^{2}$ In our case, although plasma growth hormone concentrations were $\underline{\underline{T}}$ undetectable both before and after operation, the rapid growth, 3 tall stature and enlarged pituitary fossa substantiated the $\stackrel{\mathbb{D}}{\Omega}$ diagnosis. Galactorrhea and the results of immunoperoxidase $c$ staining indicated that it was due to a pituitary adenoma $\widehat{\triangle}$ secreting growth hormone and prolactin. A spontaneous endo- $\bar{\exists}$ crine "cure" occurred after pituitary apoplexy as hypopituitarism was present preoperatively. Growth velocity had decreased क during the previous year. During this time spontaneous de- $O$ generative changes in the pituitary adenoma such as reparative fibrosis or calcification may have occurred, which presumably arrested the activity of the adenoma.

Treatment of pituitary apoplexy requires excision of the tumour and postoperative irradiation. Recurrence may occur if $\overline{\overline{0}}$ the necrotic mass is left. ${ }^{4}$ Selective transphenoidal microsurgery $\vec{\nabla}$ in the early stage is the ideal treatment for pituitary adenoma. ${ }^{5} \Omega$ Early recognition and selective removal of adenomas offers the क⿻ best chance of preserving normal pituitary function in children $\overrightarrow{0}$ with gigantism.

\section{References}

${ }^{1}$ Sachdev Y, Copal K, Garg VK, Mongia SS. Pituitary apoplexy (spontaneous pituitary necrosis). Postgrad Med f 1981 ;57:289-93.

2 Pelkonen R, Kuusisto A, Salmi J, et al. Pituitary function after pituitary oj apoplexy. Am $\mathcal{F}$ Med 1978;65:773-8.

${ }^{3}$ Whitehead EM, Shalet SM, Davies D, Enoch BA, Price DA, Beardwell œ CG. Pituitary gigantism: a disabling condition. Clin Endocrinol 1982; $\overrightarrow{0}$ $17: 271-7$.

4 Sachdev Y, Evered DC, Hall R. Spontaneous pituitary necrosis. Br Med $\mathcal{J}$ $1976 ; \mathrm{i}: 942$

5 Quabbe HJ. Treatment of acromegaly by trans-sphenoidal operation, 90-yttrium implantation and bromocriptine: results in 230 patients. Clin Endocrinol 1982;16:107-19.

(Accepted 15 fune 1983)

\title{
Arteriovenous haemofiltration: a recent advance in the management of renal failure
}

\author{
N J DODD, R M O'DONOVAN, D N BENNETT-JONES， P B RYLANCE，M BEWICK, V PARSONS, \\ M J WESTON
}

\author{
Abstract \\ Twenty five patients with oliguric renal failure were \\ treated by a combination of continuous arteriovenous \\ haemofiltration and intermittent haemodialysis over 18 \\ months. Haemofiltration was given for a mean of 6.6 \\ days and the mean filtration volume was $6.01 /$ day. \\ Fourteen of the 25 patients survived beyond two months \\ after the period of oliguria. \\ Haemofiltration proved to be a simple and effective \\ method of fluid removal; it allowed maintenance of stable

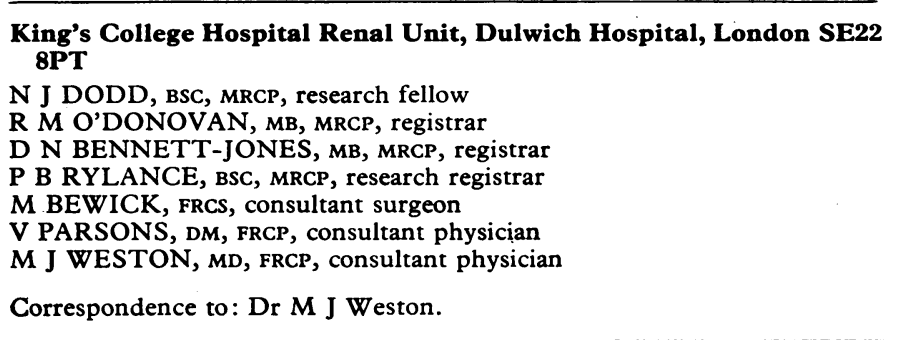

fluid balance and permitted optimum nutrition during prolonged oliguria.

\section{Introduction}

Fluid overload is a common life threatening problem in various clinical conditions. In many patients appropriate fluid restriction $N$ and treatment with diuretics will correct the abnormality, but in renal impairment such measures may be ineffective or inappropriate and dialysis may be required. Haemodialysis with ultrafiltration is efficient in removing fluids but demands skill and equipment which may not be available, and may impose $\stackrel{\mathcal{D}}{\rightarrow}$ excessive stress on the patient's cardiovascular system. Peritoneal 0 dialysis, though more readily available, may not be applicable o after abdominal surgery or trauma, and the attendant protein $\stackrel{\mathbb{D}}{\mathbb{D}}$ loss may exacerbate hypoproteinaemia and reduce tissue $\mathbb{\mathbb { D }}$ perfusion. In patients with oliguric renal failure adequate nutrition via enteral or parenteral routes is often severely restricted by the inherent fluid load. This limitation results in 8 suboptimal energy intake with exacerbation of the catabolic state or the need for frequent, often daily haemodialysis. 
A novel therapeutic device has recently become available in Britain which obviates many of these problems by providing an easily adjustable fluid output, thus allowing unrestricted nutrition and reducing the need for haemodialysis.

\section{Description and method of use}

Device and circuit - The Amicon Diafilter is a hollow fibre haemofilter constructed from a highly permeable polysulphone membrane and is available in two main sizes, $0 \cdot 2$ square metre (Diafilter 20) and 0.6 square metre (Diafilter 30 ). In all of the patients reported here we used the small filter (blood volume less than $12 \mathrm{ml}$ ), which provides an adequate fluid output of up to $15 \mathrm{l} / 24$ hours and results in a lower pressure gradient in the blood compartment than with the larger filter, thus reducing the incidence of clotting. Blood inflow and outflow ports are sited at each end (figs 1 and 2) and are connected by short tubing to any suitable arteriovenous access. No blood pump, bubble

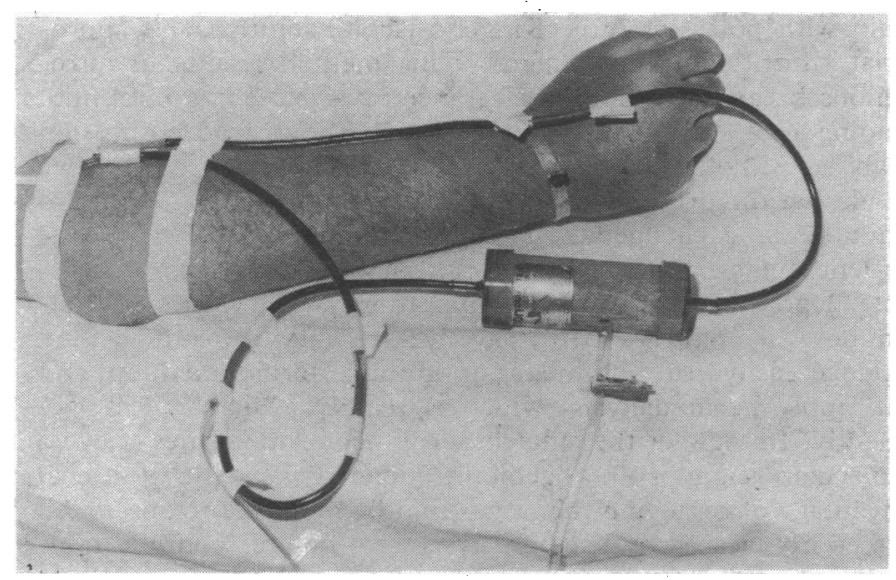

FIG 1-Amicon 20 Diafilter in use.

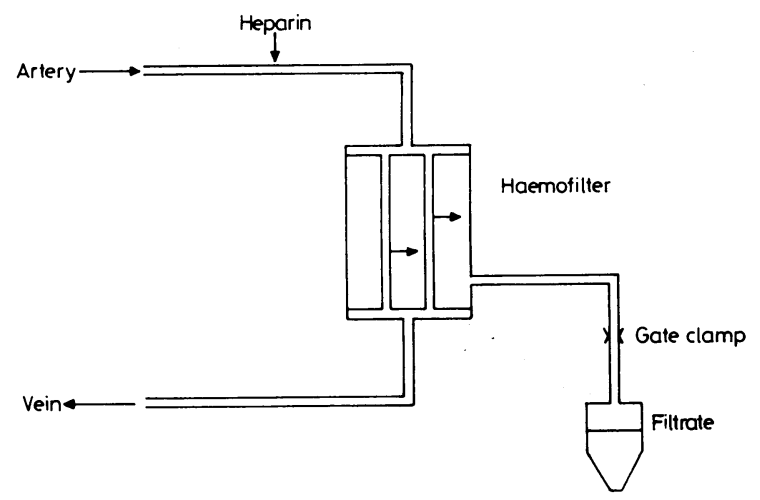

FIG 2-Haemofiltration circuit diagram.

trap, or monitoring equipment is necessary as the circuit is closed and operates entirely by virtue of the patient's blood pressure. Heparinisation of the haemofilter inflow blood is usually necessary and may be provided by a continuous infusion pump. Filtrate leaves the haemofilter by a single side mounted outflow port and can be collected in a conventional urimeter, which should be placed at least $40 \mathrm{~cm}$ below the filter. Control of filtration rate is achieved simply, by applying a gate clamp to the filtrate outflow tubing.

Access-Quinton-Scribner arteriovenous shunts were used for most patients but access may be achieved by cannulation of the femoral artery and vein by the Seldinger technique. ${ }^{1}$ On one occasion blood was returned to the patient via a central venous catheter while using brachial artery access.

Filtrate-The filtrate closely resembles unmodified glomerular filtrate. The low molecular weight solute content is identical with that of the plasma, and clearance rates of urea and creatinine are thus the same as the filtration rate. The molecular size cut off is roughly 10000 daltons; hence no appreciable loss of protein occurs, whereas amino acids are filtered freely. ${ }^{2}$ Predictably, and as an incidental benefit, calcium is present in its ionised form only, thus providing a measure of the ionised proportion of total plasma calcium. Conjugated bilirubin is filtered, while the unconjugated protein bound rroportion is retained. If filtration is not restricted, up to 151 a day may be produced, depending on blood pressure, blood flow, and the packed cell volume.

\section{Patients and results}

Twenty five patients with oliguric renal failure were treated over 18 months. Their age range was $28-68$ years. In 18 cases the oliguria was precipitated by operation (8), trauma (2), pancreatitis (2), rhabdomyolysis (3), and septicaemia (3); in six by acute on chronic renal failure; and in one by failure of a renal transplant.

Haemofiltration was given for a mean of 6.6 days (range 2-28), and the mean filtration volume was $61 /$ day. Haemodialysis was applied every third or fourth day. The mean life of the haemofilters was 46 hours.

Of the 25 patients, 14 survived more than two months after the period of oliguria (survival rate $56 \%$ ).

Case 1-A 63 year old woman with chronic renal failure due to pyelonephritis presented with pulmonary oedema and acute oliguria precipitated by septicaemia. Peritoneal dialysis failed to control the uraemia or to remove sufficient fluid, and haemodialysis was ruled out by virtue of her hypotension. Haemofiltration was therefore started at $300 \mathrm{ml} /$ hour using an arteriovenous shunt while initially continuing peritoneal dialysis to provide additional solute and electrolyte clearance. In this way fluid overload was successfully corrected, cardiac output improved, and her blood pressure rose. She was then maintained for 10 days on continuous haemofiltration, with intravenous fluid and nutritional replacement and intermittent haemodialysis, which was applied every third day. (Peritoneal dialysis was discontinued after 12 hours of haemofiltration.) She subsequently recovered from the acute illness and was treated with intermittent peritoneal dialysis until her death six weeks later of a cerebrovascular accident.

Case 2-A 50 year old woman presented with acute oliguric renal failure as a consequence of legionnaires' disease. She was severely catabolic and haemodialysis was required daily to control uraemia. This was poorly tolerated, however, and was difficult to provide as often as necessary. She was therefore established on haemofiltration with an output of $5 \mathrm{l}$ daily with appropriate fluid replacement and intermittent haemodialysis every third or fourth day. Figure 3 shows the second of two periods of combined haemofiltration and haemodialysis. Very satisfactory control of uraemia was achieved, particularly as the catabolic state lessened in response to adequate nutrition. She subsequently made a good recovery after a total of six weeks of oliguria, during which she underwent haemofiltration for a total of 28 days.

In all patients, once fluid overload had been corrected by unrestricted filtration, the gate clamp was applied, reducing filtrate volume to about 61 daily. This output was matched by an equivalent

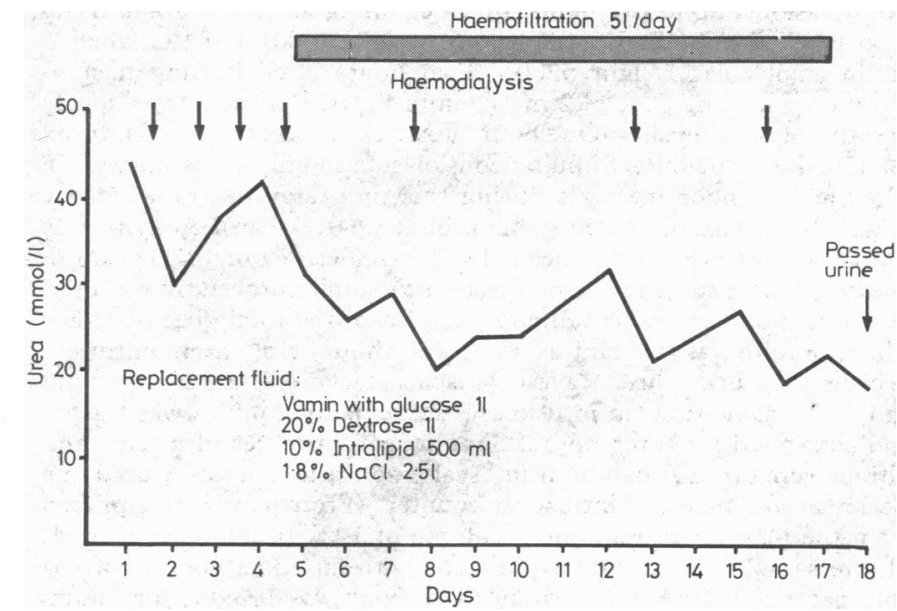

FIG 3-Case 2. Plasma urea response to haemofiltration.

Conversion: SI to traditional units-Urea: $1 \mathrm{mmol} / 1 \approx 6 \mathrm{mg} / 100 \mathrm{ml}$. 
input of fluid, of which half comprised intravenous nutrition (sodium content $70 \mathrm{mmol}(\mathrm{mEq})$ ) and the rest $1.8 \%$ sodium chloride in an appropriate volume to maintain sodium balance. Figure 4 shows a typical fluid regimen. We avoided the administration of fluids or

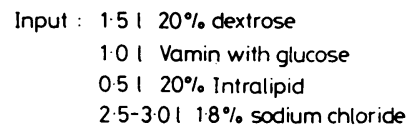

Output: 61 tiltrate

FIG 4-Typical haemofiltration fluid regimen.

blood products into the haemofilter blood lines, since this may impede blood flow and thus shorten the life of the haemofilter. The use of intravenous lipids during haemofiltration resulted in filter occlusion when serious lipaemia was produced, but was uncomplicated if the lipid was administered slowly. Blood flow rates as measured by air bubble injection ranged between 20 and $40 \mathrm{ml} / \mathrm{min}$ and varied with blood pressure.

Reduction of filtration output to 61 daily resulted in a urea and creatinine clearance of $4.2 \mathrm{ml} / \mathrm{min}$, sufficient to reduce the rate of rise of plasma urea and creatinine concentrations. Haemodialysis was therefore required less often (every third or fourth day) and fluid removal was unnecessary, since the patients were in fluid balance. Gambro AK10 bicarbonate dialysis machines were used with open circuit ultrafiltration monitoring and zero transmembrane pressure, resulting in low fluid loss and well tolerated dialysis.

Heparinisation requirements were low (mean $750 \mathrm{U}$ Leo porcine mucosal heparin/hour). The heparin dose was monitored on haemofilter outflow blood by use of Hemochron activated whole blood clotting times, which were maintained at $30-60 \mathrm{~s}$ over baseline. Heparin concentrations in the haemofilter outflow blood were between 300 and $600 \mathrm{U} / \mathrm{l}$, while systemic heparinisation was less than $200 \mathrm{U} / \mathrm{l}$. Life of the haemofilters varied between 24 and 72 hours with a mean of 46 hours, though many were discarded before haemodialysis despite remaining fully functional. (The arteriovenous shunt was required for haemodialysis.)

The biocompatibility of the device was assessed in six patients. Platelet count, neutrophil count, pressure of arterial oxygen, and complement activation fragment $\mathrm{C} 3 \mathrm{~d}$ (two patients) were measured before and at 15, 60,120, and 240 minutes after beginning haemofiltration. There was no fall in platelet or neutrophil count, no hypoxia, and no increase of plasma C3d. This contrasts with haemodialysis with cuprophane membranes, where neutropenia and a fall in platelet count occur, hypoxia is induced, and C3d concentrations rise. ${ }^{3}$

\section{CLEARANCE EFFICIENCY $\left(\mathrm{C}^{\circ}{ }_{0}^{\circ}\right)$}

Urea and creatinine are present in plasma and filtrate in identical concentrations, so that by using the simple calculation $\mathrm{C} \%=$ (filtrate concentration $\times 100$ )/plasma concentration, each is found to have a $\mathrm{C} \%$ of 100 . Clearance efficiency of larger molecules was measured on two occasions, up to five hours after beginning haemofiltration, using ${ }^{58}$ Co labelled vitamin $B_{12}$ (molecular weight 1400 ) and ${ }^{14} \mathrm{C}$ labelled inulin (molecular weight 5200). Two hours after starting haemofiltration a loading dose of $2 \mathrm{mg}$ vitamin $\mathrm{B}_{12}$ was given intravenously to saturate binding sites. One hour later ${ }^{58} \mathrm{Co}$-vitamin $B_{12}$ was infused for a further two hours. Simultaneous plasma and filtrate samples were taken at half hour intervals during this time and the radioactivity measured in an automated gammacounter (Beckman). Activity was similar at all times with a mean clearance efficiency of $101 \cdot 3^{\circ}{ }_{0}$ up to five hours after starting haemofiltration. A similar procedure was used to assess inulin clearance. Eighty per cent of the total dose of radiolabelled inulin was given intravenously one hour before haemofiltration in order to saturate the extravascular space. Haemofiltration was begun and at the same time an infusion of the remaining inulin was started and continued for three hours. Simultaneous samples of plasma and filtrate were taken at half hour intervals and the activity measured in a Beckman automated scintillation counter. (Frotein was precipitated from the plasma with an equal volume of $12 \%$ trichloroacetic acid: filtrate samples were similarly diluted with an equal volume of trichloroacetic acid.) Mean clearance efficiency was $103.8 \%$ for inulin. Albumin is not filtered and can therefore be ascribed a clearance efficiency of nil.

\section{Discussion}

Arteriovenous haemofiltration proved to be a safe, effective method of fluid removal. In this group of 25 patients 14 survived at least two months beyond the period of oliguria. A survival rate of $56^{\circ}$ is not significantly better than expected in acute renal failure treated conventionally. The management of these patients was significantly simplified by this procedure, however, with smoother control of uraemia, improved fluid balance, and liberal nutrition.

In addition to its use in renal failure, it has potential application in other cases of intensive care medicine. Short term haemofiltration for fluid removal during cardiopulmonary bypass has been described, ${ }^{4}$ and a similar technique has been applied as an isolated procedure to correct fluid overload in an intensive care unit. ${ }^{5}$ Burnt patients who suffer life threatening protein loss might also be helped by this technique, which would aid plasma water removal and facilitate protein replacement.

Continuous haemofiltration as a replacement for haemodialysis has been developed in Germany.' Kramer et al removed 15-20 1 of filtrate daily by unpumped haemofiltration and replaced the fluid with potassium free Ringer's lactate solution and appropriate nutritional supplements. This method results in nitrogenous breakdown product clearance rates exceeding $8 \mathrm{ml} / \mathrm{min}$, leading to a steady state and obviating the need for diffusion dialysis. Although this approach is undoubtedly successful, we think that the procedure is complicated by the large volumes of fluid being exchanged, which are an additional risk to the patient: small errors in fluid balance might result in an unacceptable degree of overload or dehydration. With restricted continuous haemofiltration $(6 \mathrm{l} /$ day) we are able to maintain fluid balance easily, can administer optimum calorific nutrition, and can apply haemodialysis (which is readily available) less frequently. In view of the efficient clearance of molecules above a molecular weight of 5000 haemofiltration may have the additional advantage of removing the larger middle molecule toxins, which are poorly cleared by haemodialysis. ${ }^{6}$ No notable complications of the procedure occurred during this study. Hypotension was not encountered unless unrestricted filtration was applied to an unstable patient. If necessary, during periods of hypotension the filtrate outflow line may be clamped off completely without disturbing blood flow through the filter. No serious blood leaks occurred, although small leaks were observed on three filters from a faulty batch, and two others occurred as a result of applying too high a pressure during priming with saline. There were no infectious complications.

We regard continuous haemofiltration as a routine, integral part of the management of oliguric renal failure. At a cost of about $£ 45$ for a haemofilter it represents not only a simple and efficient renal replacement therapy but also an economical one. It allows maintenance of a very stable fluid and nutritional state, is well tolerated, has no side effects, and may improve the outlook of these patients.

\section{References}

${ }^{1}$ Kramer P, Schrader J, Bohnsack W, Grieben G, Grone HJ, Scheler F. Continuous arteriovenous haemofiltration. A new kidney replacement therapy. Proc Eur Dial Transplant Assoc 1981;18:743-9.

${ }^{2}$ Kramer P, Kaufhold G, Grone HJ, et al. Management of anuric intensive care patients with arteriovenous haemofiltration. Int $\mathcal{f}$ Artif Organs $1980 ; 3: 225$.

${ }^{3}$ Dodd NJ, Vergani D, Turney JH, Parsons V, Weston MJ. Complement activation and Clq binding activity in haemodialysis. Proc Eur Dial Transplant Assoc 1981;18:300-4.

+ Darup J, Bleese N, Kalmar P, Lutz G, Pokar H, Polonius MJ. Haemofiltration during extracorporeal circulation. Thorac Cardiovasc Surg $1979 ; 27: 227-30$.

${ }^{5}$ Pourrat JP, Dueymes J, Faure A, Conte JJ. Isolated ultrafiltration in the treatment of fluid overload. Kidney Int $1981 ; 20: 310$. (Abstract.)

6 Man NK, Funck-Brentano JL. Hemofiltration, an alternative method for treatment of end stage renal failure. Adv Nephrol 1977;7:293-310.

(Accepted 14 fune 1983) 